\title{
KEEPING DOWN WITH THE JONESES: NEIGHBORS, NETWORKS, AND WAGES
}

\author{
Manuel Pastor, Jr. and Ara Robinson Adams*
}

\begin{abstract}
This paper looks at the effects of neighborhood location on wages for a sample of male workers in Los Angeles County. Controlling for the usual human capital and social variables, the poverty of one's neighborhood has a dampening effect on earnings, presumably because of the "lower quality" of job networks available in poor areas. This "concentrated poverty" or "network" effect seems to be more important in this sample than "spatial mismatch" or distance from employment; nonetheless, commuting (as well as moving) out of a poor neighborhood tends to raise wages, giving some support for recent policy attempts to increase the residential and employment mobility of inner-city residents.
\end{abstract}

\section{INTRODUCTION}

In 1994 and 1995, the Department of Housing and Urban Development began to roll out its new "Moving to Opportunity" (MTO) program. Modeled on the Gautreaux program implemented in Chicago, MTO was designed to assist low-income inner city residents with Section 8 rental assistance in moving to units in suburban neighborhoods. The hope behind promoting such mobility was straightforward: escaping the concentrated poverty of the inner city was supposed to raise economic expectations and outcomes for poor individuals and thereby allow them to achieve a higher degree of self-sufficiency. ${ }^{1}$

But does location matter? And if it does, how important is it in Southern California, an area where long-distance commuting is a seemingly indelible characteristic of local culture? In this paper, we explore the impact of neighborhood residence in wage determination in Los Angeles County. Our central argument is that the poverty of one's neighbors affects the "quality" of one's job networks and hence one's income; in short, if you live in a place where most individuals have either no jobs or "bad" jobs, you are more likely, if employed, to receive lower wages.

To demonstrate this point, we conduct wage regressions which include both the usual human capital and social variables and a locational measure based on

\footnotetext{
*Associate Professor of Economics and Director of the International and Public Affairs Center, Occidental College, Los Angeles; and Research Associate, International \& Public Affairs Center, Occidental College, Los Angeles. Thanks to the John Randolph Haynes and Dora Haynes Foundation and Occidental College for their support of this research. Thanks also to Peter Dreier, Rob Fairlie, George Galster, and two anonymous referees as well as members of the Economics Departments of Occidental College, USC, and UC-Riverside for comments on earlier drafts; special thanks to Robby Moore for his constant support and constructive criticism of this project.
} 
neighborhood poverty. We also consider the rewards to commuting, particularly when the commute involves a daily exodus from high poverty areas of residency to less poor areas of employment (and presumably to more effective workplacebased social networks). The results suggest that neighbors and networks do indeed have an important effect on economic performance: higher "quality" networks raise an individual's wage outcome.

The negative impact of living in a poor area has been the focus of other statistical exercises. The novelty here emerges from five factors. First, we do not compare economic outcomes in cities and suburbs from a pooled set of metropolitan areas, but rather break up a single economic region, Los Angeles County, into 58 different broad "neighborhoods." This allows for superior control-our data are all from the same region and metropolitan labor market-and permits a more detailed or refined accounting of neighborhood effects. Second, we make even better use of this breakdown by moving beyond the usual approach of using dummy variables for area (i.e., city vs. suburb) and instead generate quantitative measures which offer a continuous measure for the effectiveness of neighborhood networks. Third, we concentrate our research on wages and not employment probabilities, partly because a large proportion of the poorest residents in Los Angeles are not the sort of traditional "underclass" of Eastern cities but rather the working poor. For this latter group-a large number of whom are Latino-labor force participation and employment rates are high, and wages may be a better measure of network effectiveness. ${ }^{2}$ Fourth, we attempt to distinguish between any negative wage impacts due to the concentrated poverty of an individual's neighborhood (i.e., the "network" effect) and the "spatial mismatch" some neighborhoods suffer due to distance from job opportunities. Finally, in at least one set of regression runs, we move beyond the usual approach in the literature and control for the simultaneity of wage outcomes and location decisions.

The paper proceeds as follows. We begin below with a review of the theoretical arguments and empirical literature on location and economic outcomes. We then turn to our own approach, detailing both the equation to be estimated and the construction of this particular data set. We then review the results of various regression exercises, including runs which look at the outcomes for specific ethnic groups. Finally, we summarize the overall argument and draw some relevant policy lessons.

\section{LITERATURE REVIEW}

The idea that inner city locations, particularly areas of concentrated poverty, can have negative impacts on individual economic performance has been the subject of much theorizing and numerous studies. The initial impetus was John 
Kain's work suggesting that the poor outcomes of Blacks in the labor market were due partly to housing segregation patterns that prevented African-Americans from moving in pace with the suburbanization of employment (Kain, 1968). This "spatial mismatch" hypothesis was later stressed by Wilson (1987) in his analysis of the "underclass:" living where the jobs aren't, it is argued, has a negative effect on employment, particularly when fixed rail and bus lines are not conducive to "reverse commuting." ${ }^{3}$

Acs and Wissoker (1991) add that living in areas of concentrated poverty and joblessness may also be a problem because residents develop "a self-perpetuating sub-culture isolated from mainstream society" (Acs and Wissoker, 1991, p.1). This culture, it is argued, encourages behavior which is inappropriate to regular employment, and therefore, success in job-seeking becomes less probable. Even if any particular individual does not exhibit "underclass behavior," employers may take address as a signal of underclass membership and discriminate accordingly, with negative effects above and beyond the usual racial bias. ${ }^{4}$ This "contagion effect" caused by living in an underclass area-whether real in its behavioral effects or imagined by signal-reliant employers-illustrates that it is not simply locational distance from employers that is significant to determining economic outcomes. One can, for example, imagine groups of individuals who live far from employers but nonetheless manage to secure employment and reasonable wages; the commuters who drive an hour and a half from middle-class Palmdale to downtown Los Angeles do not seem to suffer economic consequences because of their territorial marginalization from employment opportunities. What matters beyond one's individual skills, it seems, is the type of neighborhood one lives in and the economic prospects and connections contained within one's neighborhood.

Why is this so? Reviewing a variety of survey results, $O^{\prime}$ Regan notes that a vast majority of successful job seekers learn about job opportunities either because they themselves work at an establishment with vacancies or because they know someone who does. Employers, in turn, may rely on current employees to provide referrals of new employees, partly to reduce their own costs of information-gathering. ${ }^{5}$ For both sides of the labor market, then ${ }_{2}$ social "networks" are important and have an impact on wages above and beyond that of individual human capital or skills. Most critically, these networks "are largely determined by location" and "there is a negative externatity associated with increased concentration of the poor" (O'Regan, 1993, p.331). In short, network quality matters to individual job-seekers and the economic situations of one's neighbors provide either positive or negative externalities.

In investigating the effects of networks and location on economic outcomes, researchers have frequently focused on the probability of employment. Performing the requisite logit regressions, many researchers obtain results consistent with 
the spatial mismatch and poverty concentration hypotheses: While a few researchers suggest that it is race, not residence, which is critical to predicting employment (Acs and Wissoker, 1991; Ellwood, 1986), the general pattern is quite conducive to those that stress the negative impacts from inner-city residence (see O'Regan, 1993; Ihlanfeldt and Sjoquist, 1990a, 1990b; and Ihlanfeldt, 1992) and this set of results has certainly been influential in providing a basis for the recent policy emphasis on enhancing housing and employment mobility.

There are, however, several shortcomings to this body of research. First, much of the research uses a definition of location which is sometimes too broad to capture our focus on the potential impact of neighbors and networks on individual wages. Several groups of studies, for example, pool multiple metropolitan areas and distinguish only between central city and suburban residents (see Sexton, 1991; Price and Mills, 1985). ${ }^{6}$ Studies which do concentrate on one metropolitan area employ "neighborhoods" that are exceptionally large. Ihlanfeldt and Sjoquist (1990a), for example, divide metro Chicago into seven zones-the city of Chicago, other parts of Cook County, and five adjoining counties, while Ihlanfeldt (1992) reduces New York to thirteen zones-the five counties that form the City of New York, two suburban counties in New York state and seven counties in New Jersey. ${ }^{7}$ Proxying the concept of "network" with such large geographic and socially diverse spaces seems problematic.

This scale problem is particularly difficult if one tries to apply the same "central city, surrounding counties" approach to Los Angeles. L.A. is the nation's largest city in terms of land area and, as a result, contains many of its own suburbs. The City, moreover, shares a county with 88 other municipalities, some of which are "inner ring" suburbs with economic conditions often as bad as those of inner city L.A. ${ }^{8}$ In short, using a traditional city-suburb division will not let us determine the effect of neighborhoods and networks in this Southern California "mega-city"; we need instead a much finer breakdown of neighborhoods.

A second shortcoming of most studies is the focus on employment. While this is certainly a key variable, network quality should be judged not simply on whether jobs are obtained but also on what sort of jobs are in the neighborhood social orbit. This is particularly important in L.A., where at least one key group residing in the inner city, Latinos, exhibits extremely high rates of labor force participation-and hence a high probability of employment-but also very high rates of poverty (Pastor, 1993). In this case, the relevant measure of economic well-being, particularly for testing network "quality," may be worker income.

Wage regressions have, however, not been common in the literature. One study by Price and Mills (1985, p.17) does find that central city location dampens wages but concludes that the effect is "small for blacks, and is probably as high for whites as for blacks." Sexton (1990) also finds location to be a significant fac- 
tor in determining wages but suggests that the locational "penalty" for central city residence is larger for Blacks. Unfortunately for our purposes, both articles utilize the extremely large zones (city-suburb) we have already faulted and therefore also use a pooled multi-city sample, a strategy which creates its own problems of cross-region comparability. Moreover, the Price and Mills study has no information on the workplace location of the individuals in the sample, primarily because they use the Current Population Survey, a database that does not include this measure. Sexton uses the Public Use Microdata Sample and so has some information on work sites; however, he uses the broadest possible categories on workplace (i.e., city vs. suburb) rather than the more refined breakdown employed below.

The aforementioned wage studies do have one advantage: they look at earnings for adults. Many of the studies focusing on employment probability look only at youth labor markets. While the concentration on youth emerges partly because of a specific policy interest in youth labor markets, some researchers also focus on the young to avoid the simultaneity issues involved in residence and employment decisions. After all, while poor neighborhoods may reduce employment connections, reduced employment connections can also shrink income and force a move to poorer (lower-rent) locales; thus, location may not he strictly a right-hand side or exogenous variable. Teens, it is suggested, do not decide where they live-their parents do-and the study of youth employment sidesteps this simultaneity problem.

This logic, however, is a bit strained. If causality does indeed also run from economic outcomes to neighborhood location, then focusing on teens does not fully overcome the issue: bad outcomes for location-deciding parents and their inhouse teens are closely associated, and the residence of a teen is therefore at least indirectly a product of his/her employment probability. Fortunately, simultaneity may be less of a problem with a continuous variable like wages than with a dichotomous variable like employment. If we regress individual characteristics (education, experience, race, etc.) on a wage and the wage also determines what sort of neighborhood you live in, then adding a neighborhood variable should result in insignificance-the neighborhood choice is determined by the same factors that determine the wage and hence should be redundant. ${ }^{9}$ Following this logic, the residence and wages literature has been less concerned with issues of simultaneity than has the residence and employment literature. ${ }^{10}$

In this paper, we mostly follow the general direction of that literature and assume that the causal structure from location to wages is appropriately captured by a typical ordinary least squares (OLS) wage regression. Toward the end of our empirical section, however, we attempt to control for simultaneity via two stage 
least squares. The results, as we will see, are consistent with the general trends emerging from the simpler OLS methodology.

To summarize, much of the literature concludes that there is a locational cost associated with inner city residence, both because of spatial mismatch and because of network "quality." However, additional research which focuses on wage effects uses finer-grained neighborhood zones, and tackles simultaneity, may both fill a few gaps in the literature and better suit an analysis of Los Angeles. Finally, separating out the spatial and network factors which are often conflated in past research may also contribute to our understanding and policy-making.

\section{DATA, VARIABLES, AND REGRESSION DESIGN}

Our goal is to conduct a wage regression which includes not only the usual human capital and social determinants but also measures of neighborhood "quality." We also want to see if there are differential returns to commuting from high- and low-poverty neighborhoods; and we particularly wish to evaluate the impact of commuting from a poorer to a richer neighborhood, a daily exodus which presumably ties one in to a higher "quality" network of co-employees.

The main database used in this analysis is the 1990 five percent Public Use Microdata Sample (PUMS) for Los Angeles County. This database contains annual earnings and time worked as well as the usual battery of human capital (education, experience, language skills) and other determinants of wages (race, marital status), all recorded for individuals . PUMS also conveniently records the residence and workplace (if any) location of each individual, making it seemingly ideal to test neighborhood effects.

The geographic identifier in the PUMS data is the Public Use Microdata Area (or PUMA). These PUMAs consist of relatively large aggregations of census tracts, with the aggregation employed because of the worry that tagging an individual with a census tract number might make it easy to identify him/her and hence erode the confidentiality of the census process. Despite the necessary aggregation, many large metro areas have multiple PUMAs-the City of Los Angeles has 21 , while the surrounding County contains another 37-and this allows for both finer distinctions within the so-called central city and helps us distinguish the quality (or wage-enhancing properties) of different suburbs.

As noted in the literature review, many studies lose much of this information by simply sorting respondents into aggregate categories of central city or suburb and then pooling across metropolitan areas. Studies that do break metropolitan areas up into slightly finer categories seem to use aggregations of PUMAs (which are, as noted, already aggregations of tracts). Even those with finer breakdowns make little real use of the geographic distinctions; a barrage of dummy variables 
proxy for location, but there is little attempt to quantitatively rank locations in order to determine "quality." One exception is Ihlanfeldt and Sjoquist (1990b), who do introduce an average travel time measure for each zone they determine. Such a travel time variable, however, seems to be consistent with a range of network quality-one can easily imagine lengthy commutes from both wealthy and poor neighborhoods-which is why we focus on neighbor "quality" throughout our empirical analysis. As we will see, introducing a similar distance variable to control for potential spatial mismatch has virtually no impact on our network measure; indeed, the network quality measure far outperforms the distance measure in both individual significance and overall explanatory power.

To go beyond broad categories or dummy variables and instead determine continuous measures of neighborhood "quality," we wrote a sorting program to aggregate the tract-level data in the U.S. Bureau of the Census Summary Tape Files (STF) 1 and 3 up to the PUMA level. This procedure did not draw directly on the same PUMS sample and hence allowed, at least in theory, for more exogeneity for the calculated right-hand side variables. ${ }^{11}$ The main variable of choice, explained below, was the "neighborhood" or PUMA poverty rate.

Are the resulting 58 PUMA "neighborhoods" meaningful? They are, unfortunately, large, with population sizes averaging 150,223 and ranging from 100,672 to 429,433 (see Table 1). Nonetheless, these are the finest breakdowns available for matching with the sort of individual-level observations necessary for wage and other labor-market regressions and there does seem to be some sort of reasonable consistency within neighborhoods. Within the city of LA., for example, PUMA 6501 contains the low-income and heavily Latino neighborhoods of Lincoln Heights, Eagle Rock, Highland Park and El Sereno, while PUMA 6509 contains the affluent and largely Anglo neighborhoods of Bel Air, Brentwood, Pacific Palisades, and Studio City. Similarly, outside of L.A. city, PUMA 6300 contains the predominantly middle class and multiracial city of Pasadena, while PUMA 6100 contains the lower income and heavily minority city of Inglewood. For a geographic look at the PUMAs, see Figure 1; a full breakdown of the ethnic composition and poverty status of the various PUMAs is given in Table 2.

The base equation for our runs (prior to the introduction of neighborhood characteristics, commute time, and other variables) is fairly standard, i.e.:

\section{LNWAGE $=f($ YEARSCH $(+), \operatorname{EXPWORK~}(+), \operatorname{EXPWRKSQ~}(-)$, MARRIED (+), ENGLIM (-), IMM70S (-), IMM80S (-), $\operatorname{AFAM}(-), \operatorname{LATINO}(-), \operatorname{ASIAN}(-))$}

where LNWAGE is the natural log of hourly earnings, YEARSCH is the number of years of formal education, ${ }^{12}$ EXPWORK is the number of years of work ex- 
TABLE 1

1990 Public Use Microdata Areas in Los Angeles County

\begin{tabular}{|c|c|c|}
\hline PUMA & POPULATION & DESCRIPTION \\
\hline 5200 & 166,223 & Burbank and San Fernando \\
\hline 5300 & 180,038 & Glendale \\
\hline 5400 & 120,076 & Monterey Park and Rosemead \\
\hline 5500 & 126,379 & East Los Angeles \\
\hline 5600 & 127,934 & Huntington Park, Florence-Graham* and Walnut Park* \\
\hline 5700 & 148,229 & Lynwood and South Gate \\
\hline 5800 & 106,209 & El Monte \\
\hline 5900 & 131,723 & Pomona \\
\hline 6000 & 104,138 & Carson and West Carson* \\
\hline 6100 & 109,602 & Inglewood \\
\hline 6200 & 132,398 & $\begin{array}{l}\text { Beverly Hills, Culver City, West Hollywood, } \\
\text { Ladera Heights*, Marina del Rey*, and } \\
\text { View Park-Windsor Hills* }\end{array}$ \\
\hline 6300 & 131,591 & Pasadena \\
\hline 6401 & 236,084 & $\begin{array}{l}\text { Lancaster, Palmdale and various areas in northern } \\
\text { central L.A. county* }\end{array}$ \\
\hline 6402 & 141,472 & $\begin{array}{l}\text { Santa Clarita, Val Verde*, and various areas in } \\
\text { northwestern L.A. County }\end{array}$ \\
\hline 6403 & 139,618 & $\begin{array}{l}\text { La Canada Flintridge, Monrovia, Sierra Madre, Altadena*, } \\
\text { and La Crescenta-Montrose* }\end{array}$ \\
\hline 6404 & 106,042 & Alhambra and South Pasadena \\
\hline 6405 & 145,597 & $\begin{array}{l}\text { Arcadia, San Gabriel, San Marino, Temple City, } \\
\text { East Pasadena*, and North El Monte* }\end{array}$ \\
\hline 6406 & 139,685 & $\begin{array}{l}\text { Bell Gardens, Bell, Commerce, Cudahy, Maywood, } \\
\text { and Vernon }\end{array}$ \\
\hline 6407 & 144,089 & Compton, East Compton*, and Willowbrook* \\
\hline 6408 & 144,711 & $\begin{array}{l}\text { Azusa, Baldwin Park, Bradbury, Duarte, Irwindale } \\
\text { and Citrus* }\end{array}$ \\
\hline 6409 & 156,380 & $\begin{array}{l}\text { Claremont, Glendora, La Verne, San Dimas, } \\
\text { and Charter Oak* }\end{array}$ \\
\hline 6410 & 103,653 & Diamond Bar, La Habra Heights, and Rowland Heights \\
\hline 6411 & 157,437 & Covina, West Covina, and Vincent* \\
\hline 6412 & 111,998 & $\begin{array}{l}\text { Industry, La Puente, South El Monte, Avocado Heights*, } \\
\text { Valinda*, and West Puente Valley* }\end{array}$ \\
\hline 6413 & 159,220 & $\begin{array}{l}\text { Whittier, Hacienda Heights*, and West Whittier-Los } \\
\text { Nietos* }\end{array}$ \\
\hline 6414 & 118,741 & Montebello and Pico Rivera \\
\hline 6415 & 114,853 & $\begin{array}{l}\text { La Mirada, Santa Fe Springs, East La Mirada*, } \\
\text { and South Whittier* }\end{array}$ \\
\hline 6416 & 163,405 & Artesia, Cerritos, and Norwalk \\
\hline 6417 & 139,113 & Downey and Paramount \\
\hline 6418 & 149,011 & Bellflower, Hawaiian Gardens, and Lakewood \\
\hline 6419 & 152,489 & Lomita and Torrance \\
\hline
\end{tabular}


1990 Public Use Microdata Areas in Los Angeles County (Continued)

\begin{tabular}{|c|c|c|}
\hline PUMA & POPULATION & DESCRIPTION \\
\hline 6420 & 195,581 & $\begin{array}{l}\text { Avalon, El Segundo, Hermosa Beach, Manhattan Beach, } \\
\text { Palos Verdes Estates, Ranchos Palos Verdes, } \\
\text { Redondo Beach, and Rolling Hills Estates }\end{array}$ \\
\hline 6421 & 129,410 & $\begin{array}{l}\text { Gardena, Lawndale, Alondra Park*, West Athens*, } \\
\text { and Westmont* }\end{array}$ \\
\hline 6422 & 102,219 & Hawthorne, Del Aire*, and Lennox* \\
\hline 6423 & 159,644 & $\begin{array}{l}\text { Agoura Hills, Hidden Hills, Santa Monica, Westlake } \\
\text { Village, and other small parts of Western L.A. County* }\end{array}$ \\
\hline 6424 & 103,341 & $\begin{array}{l}\text { Signal Hill, Walnut, East San Gabriel*, Palmdale East*, } \\
\text { and South San Jose Hills* }\end{array}$ \\
\hline 6501 & 237,315 & $\begin{array}{l}\text { Eagle-Rock Glassell, El Sereno, Highland Park, } \\
\text { and Lincoln Heights }\end{array}$ \\
\hline 6502 & 134,932 & Boyle Heights, Downtown, and parts of Wholesale \\
\hline 6503 & 234,621 & Central Avenue-South, Green Meadows, and Watts \\
\hline 6504 & 169,397 & Adams-La Brea and Crenshaw \\
\hline 6505 & 257,469 & $\begin{array}{l}\text { South Vermont, Vermont Square, and West } \\
\text { Adams-Exposition Park }\end{array}$ \\
\hline 6506 & 240,908 & Miracle Mile North, Wilshire Center North and South \\
\hline 6507 & 247,665 & Hollywood and part of Los Feliz \\
\hline 6508 & 188,661 & Westlake and Silverlake-Chinatown \\
\hline 6509 & 150,525 & $\begin{array}{l}\text { Bel Air, Brentwood Hills, Studio City, Pacific Palisades, } \\
\text { and parts of other areas in West L.A. San Fernando } \\
\text { Valley }\end{array}$ \\
\hline 6510 & 120,242 & North Hollywood \\
\hline 6511 & 100,672 & Pacoima \\
\hline 6512 & 130,700 & Van Nuys-Sherman Oaks \\
\hline 6513 & 103,378 & Sepulveda and part of Mission Hills \\
\hline 6514 & 120,016 & Sun Valley and Tujunga-Sunland \\
\hline 6515 & 111,882 & Sylmar, parts of Mission Hills, and Granada Hills \\
\hline 6516 & 150,541 & Canoga Park and Woodland Hills \\
\hline 6517 & 146,056 & Chatsworth, Northridge, and part of Granada Hills \\
\hline 6518 & 152,805 & Encino-Tarzana and Reseda \\
\hline 6519 & 104,101 & $\begin{array}{l}\text { Westwood-West Los Angeles, and parts of } \\
\text { Brentwood-Sawtelle and Palms }\end{array}$ \\
\hline 6520 & 195,481 & Barnes City, Mar Vista, Venice, and Westchester \\
\hline 6521 & 188,031 & Harbor City, North Shoestring, and San Pedro \\
\hline 6600 & 429,433 & Long Beach \\
\hline
\end{tabular}

Notes to table: Areas marked with an asterisk (*) are unincorporated areas of the County, defined here by the names used by the L.A. County Office of Regional Planning. PUMAs 6501 to 6521 are all part of the City of Los Angeles; we offer their neighborhood names, which are again taken from the regional planning authorities. When a PUMA includes a very small portion of a neighborhood (and most of the neighborhood is another PUMA), we drop mention here in order to focus on the central character of each PUMA. 


\section{FIGURE 1 \\ Los Angeles PUMA Map \\ (1990 Census)}

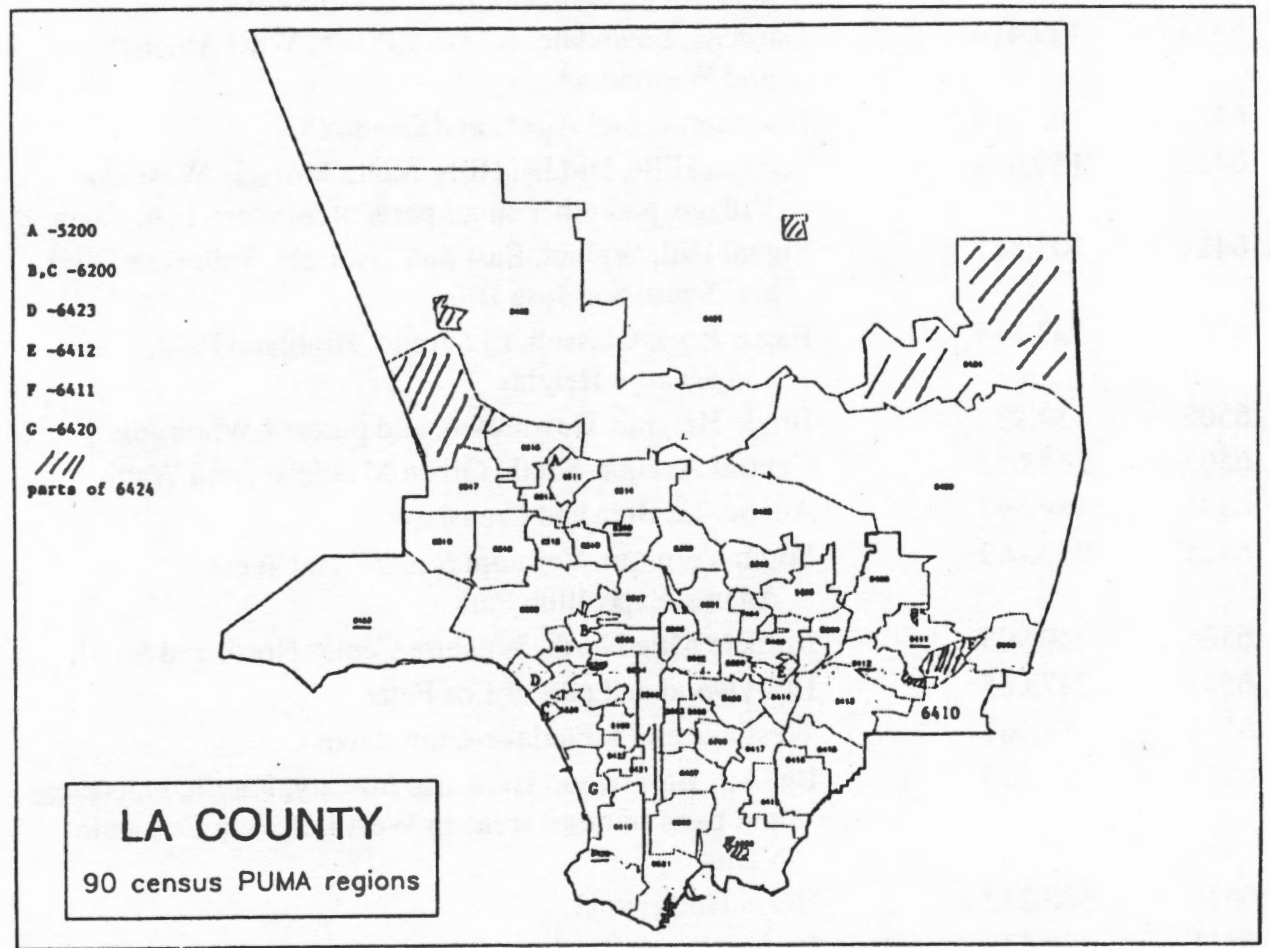

Source: Oliver, Melvin L. and David Grant, 'Los Angeles PUMA map, 1990' UCLA, Center for the Study of Urban Poverty 
TABLE 2

PUMA Characteristics: Ethnicity \& Poverty

\begin{tabular}{|c|c|c|c|c|c|}
\hline PUMA & \%Anglo & \%Af.Am. & \%Latino & \%Asn. Am. & $\%$ Poor \\
\hline 5200 & $58.3 \%$ & $1.5 \%$ & $34.3 \%$ & $5.3 \%$ & $10.1 \%$ \\
\hline 5300 & $63.7 \%$ & $1.1 \%$ & $21.0 \%$ & $13.7 \%$ & $14.4 \%$ \\
\hline 5400 & $13.7 \%$ & $0.5 \%$ & $40.5 \%$ & $44.8 \%$ & $17.8 \%$ \\
\hline 5500 & $2.8 \%$ & $1.2 \%$ & $94.7 \%$ & $0.9 \%$ & $24.2 \%$ \\
\hline 5600 & $3.5 \%$ & $9.9 \%$ & $85.3 \%$ & $0.8 \%$ & $27.3 \%$ \\
\hline 5700 & $10.6 \%$ & $9.5 \%$ & $77.8 \%$ & $1.5 \%$ & $19.3 \%$ \\
\hline 5800 & $15.2 \%$ & $0.8 \%$ & $72.5 \%$ & $11.2 \%$ & $22.5 \%$ \\
\hline 5900 & $28.2 \%$ & $13.7 \%$ & $51.3 \%$ & $6.3 \%$ & $18.4 \%$ \\
\hline 6000 & $26.8 \%$ & $22.6 \%$ & $26.9 \%$ & $23.0 \%$ & $6.6 \%$ \\
\hline 6100 & $8.5 \%$ & $50.1 \%$ & $38.5 \%$ & $2.2 \%$ & $16.5 \%$ \\
\hline 6200 & $68.4 \%$ & $14.8 \%$ & $10.2 \%$ & $6.1 \%$ & $7.4 \%$ \\
\hline 6300 & $46.6 \%$ & $17.8 \%$ & $27.3 \%$ & $7.7 \%$ & $14.9 \%$ \\
\hline 6401 & $71.9 \%$ & $6.2 \%$ & $17.7 \%$ & $3.2 \%$ & $9.4 \%$ \\
\hline 6402 & $79.3 \%$ & $1.8 \%$ & $14.0 \%$ & $4.3 \%$ & $3.9 \%$ \\
\hline 6403 & $60.1 \%$ & $15.2 \%$ & $18.1 \%$ & $6.0 \%$ & $8.8 \%$ \\
\hline 6404 & $32.8 \%$ & $2.1 \%$ & $31.0 \%$ & $33.7 \%$ & $12.5 \%$ \\
\hline 6405 & $53.6 \%$ & $0.8 \%$ & $20.3 \%$ & $24.9 \%$ & $8.2 \%$ \\
\hline 6406 & $8.9 \%$ & $0.5 \%$ & $88.8 \%$ & $1.0 \%$ & $24.6 \%$ \\
\hline 6407 & $2.8 \%$ & $52.1 \%$ & $43.2 \%$ & $1.4 \%$ & $26.6 \%$ \\
\hline 6408 & $27.9 \%$ & $3.4 \%$ & $58.7 \%$ & $9.4 \%$ & $13.5 \%$ \\
\hline 6409 & $73.9 \%$ & $3.0 \%$ & $15.6 \%$ & $7.0 \%$ & $5.1 \%$ \\
\hline 6410 & $47.7 \%$ & $4.9 \%$ & $22.1 \%$ & $24.9 \%$ & $5.3 \%$ \\
\hline 6411 & $47.8 \%$ & $6.3 \%$ & $32.5 \%$ & $12.9 \%$ & $7.7 \%$ \\
\hline 6412 & $16.3 \%$ & $2.7 \%$ & $72.7 \%$ & $7.9 \%$ & $13.6 \%$ \\
\hline 6413 & $44.7 \%$ & $1.3 \%$ & $42.3 \%$ & $11.1 \%$ & $7.5 \%$ \\
\hline 6414 & $14.9 \%$ & $0.7 \%$ & $75.4 \%$ & $8.6 \%$ & $12.8 \%$ \\
\hline 6415 & $50.3 \%$ & $1.2 \%$ & $42.6 \%$ & $5.2 \%$ & $7.8 \%$ \\
\hline 6416 & $36.8 \%$ & $4.3 \%$ & $35.6 \%$ & $22.6 \%$ & $7.5 \%$ \\
\hline 6417 & $44.3 \%$ & $5.6 \%$ & $42.1 \%$ & $7.3 \%$ & $11.3 \%$ \\
\hline 6418 & $62.2 \%$ & $4.6 \%$ & $23.2 \%$ & $9.2 \%$ & $8.3 \%$ \\
\hline 6419 & $66.7 \%$ & $1.6 \%$ & $11.2 \%$ & $20.0 \%$ & $5.9 \%$ \\
\hline 6420 & $80.8 \%$ & $1.3 \%$ & $7.9 \%$ & $9.6 \%$ & $4.4 \%$ \\
\hline 6421 & $22.6 \%$ & $32.3 \%$ & $27.6 \%$ & $16.9 \%$ & $17.1 \%$ \\
\hline 6422 & $28.0 \%$ & $20.4 \%$ & $42.6 \%$ & $8.4 \%$ & $15.6 \%$ \\
\hline 6423 & $80.6 \%$ & $3.0 \%$ & $10.2 \%$ & $5.8 \%$ & $7.1 \%$ \\
\hline 6424 & $38.7 \%$ & $7.1 \%$ & $36.7 \%$ & $17.0 \%$ & $8.4 \%$ \\
\hline 6501 & $17.8 \%$ & $1.7 \%$ & $63.8 \%$ & $16.1 \%$ & $19.5 \%$ \\
\hline 6502 & $6.0 \%$ & $6.9 \%$ & $78.8 \%$ & $7.8 \%$ & $31.6 \%$ \\
\hline 6503 & $0.7 \%$ & $39.6 \%$ & $58.6 \%$ & $0.6 \%$ & $39.5 \%$ \\
\hline 6504 & $5.2 \%$ & $61.9 \%$ & $27.4 \%$ & $4.8 \%$ & $20.8 \%$ \\
\hline 6505 & $4.4 \%$ & $47.6 \%$ & $44.7 \%$ & $2.6 \%$ & $30.9 \%$ \\
\hline 6506 & $30.4 \%$ & $12.1 \%$ & $36.4 \%$ & $20.5 \%$ & $19.9 \%$ \\
\hline 6507 & $46.2 \%$ & $4.0 \%$ & $37.6 \%$ & $11.6 \%$ & $22.0 \%$ \\
\hline 6508 & $11.8 \%$ & $2.4 \%$ & $67.4 \%$ & $17.7 \%$ & $29.9 \%$ \\
\hline 6509 & $87.7 \%$ & $1.8 \%$ & $5.9 \%$ & $4.4 \%$ & $5.4 \%$ \\
\hline 6510 & $49.5 \%$ & $4.3 \%$ & $39.7 \%$ & $6.0 \%$ & $15.6 \%$ \\
\hline 6511 & $12.8 \%$ & $10.2 \%$ & $71.8 \%$ & $4.5 \%$ & $17.5 \%$ \\
\hline 6512 & $54.7 \%$ & $4.8 \%$ & $33.8 \%$ & $6.1 \%$ & $13.5 \%$ \\
\hline 6513 & $35.4 \%$ & $6.9 \%$ & $45.9 \%$ & $11.1 \%$ & $16.0 \%$ \\
\hline 6514 & $49.1 \%$ & $2.2 \%$ & $40.3 \%$ & $7.8 \%$ & $12.1 \%$ \\
\hline 6515 & $54.3 \%$ & $3.4 \%$ & $33.6 \%$ & $8.0 \%$ & $8.3 \%$ \\
\hline 6516 & $71.4 \%$ & $2.3 \%$ & $17.6 \%$ & $8.2 \%$ & $6.9 \%$ \\
\hline 6517 & $70.7 \%$ & $2.5 \%$ & $14.7 \%$ & $11.6 \%$ & $7.5 \%$ \\
\hline 6518 & 72.3\% & $2.3 \%$ & $18.8 \%$ & $6.3 \%$ & $8.1 \%$ \\
\hline 6519 & $74.3 \%$ & $2.6 \%$ & $10.5 \%$ & $12.3 \%$ & $14.0 \%$ \\
\hline 6520 & $60.9 \%$ & $6.5 \%$ & $21.7 \%$ & $10.2 \%$ & $10.8 \%$ \\
\hline 6521 & $36.0 \%$ & $6.9 \%$ & $47.8 \%$ & $8.6 \%$ & $16.5 \%$ \\
\hline 6600 & $49.5 \%$ & $13.2 \%$ & $23.6 \%$ & $12.9 \%$ & $16.8 \%$ \\
\hline
\end{tabular}


perience (proxied as age minus years of education minus five), EXPWRKSQ is the last variable squared (in line with the notion that experience has a diminishing positive impact on earnings), MARRIED is a dummy variable equal to one if an individual is married, ENGLIM refers to English speaking ability, IMM70s is a dummy variable equal to one if the individual arrived in the United States in the 1970s, IMM80s is equal to one if arrival was in the 1980s, and AFAM, LATINO, and ASIAN are dummy variables for ethnicity, with the "control" group being Anglos. ${ }^{13}$ The signs in the parentheses indicate the expected direction of effect, with those directions being fairly standard. Given the semi-log form, coefficients generally indicate the percentage effect of a right-hand side variable on the wage.

The actual regression sample was derived by taking the L.A. County PUMS observations (about 500,000) and selecting only those who were male year-round full-time workers in the previous year (since the income figures in PUMS used to determine the hourly wage are reported for the year before the Census itself). The resulting number was still quite large $(145,511)$, and so we sampled down to hit a target of roughly 10,000 observations. Following the strategy of DeFrietas (1991), we sought to end up with roughly equal numbers of Anglos, African-Americans, Latinos, and Asian Pacifics so that we could better compare ethnic-specific regressions. We therefore employed a sampling strategy that took into account both the percentage of any ethnic group in the overall population and the usual rate of labor force participation of men of that ethnicity. As a result, Anglos and Latinos are undersampled, while Blacks and Asians are oversampled. The total sample ended up at slightly over 11,000, with Anglos comprising 29 percent, African-Americans 20 percent, Latinos 25 percent, and Asians 26 percent. ${ }^{14}$

To the base wage regression, we added two sorts of variables. The first sort involved basic neighborhood effects. The essential variables here were HPOVPCT and AVGTRHR, where the first was the household poverty rate for the PUMA in which an individual resided, and the second was the average travel time (in percent of an hour) from home to work for all working residents in the individual's PUMA of residency. ${ }^{15}$ HPOVPCT is our primary variable of interest, as this connects more precisely to the network story we emphasize; AVGTRHR is introduced primarily to control for potential spatial mismatch.

The second set of variables tested for the returns to mobility and included TRAVHRS, a measure of the time an individual spent commuting to work. ${ }^{16} \mathrm{We}$ also interacted TRAVHRS with residency poverty rates to see whether there was a higher percentage return for commuting from poor areas. A confirmation of such a higher return would accord with either a notion of spatial mismatch, in which further travel allows one to keep pace with suburbanized opportunities, or a notion of social mismatch, in which outward commuting raises the probability that one will have higher "quality" job-based networks. In the resulting regres- 
sions, we tried to control for the spatial factor by reintroducing the average travel time for all fellow PUMA residents, AVGTRHR. We also ran regressions with a variable indicating the "economic direction" of commuting; our expectation was that working in a wealthier area improves one's employment networks and hence should have a positive effect on wages.

Finally, we tackled the simultaneity issue with two strategies. First we ran the basic regressions described above for only those who have been in the neighborhood for a long period. Our logic was that non-movers were less likely to have their location determined by the current wage for reasons explained below. Our second approach included (1) specifying a very simple underlying model of locational decision in which worker income was one right-hand side variable; and (2) using the resulting instrumental variables to run a two-stage least squares regression that could take account of that direction of causality (from wages to housing choice) even as we test for the impact of neighborhood poverty on individual wages. Let us now turn to the empirical results of these different exercises.

\section{IV.RESULTS}

Table 3, Column (a), reports on a base regression employing only the usual human capital and social/race factors (i.e., we assume discrimination exists and so add race/ethnicity as dummy variables). The regression performs well: all variables are appropriately signed and highly significant and the adjusted $\mathbf{R}$-squared is 0.335, a fairly normal level of explanatory power for such a wage regression. Looking more closely at the coefficients, which in this semi-log equation tell us the percentage effects of a variable on the wage level, we see that the two dummy variables with the largest impact on wages are IMM80s and AFAM. In this Los Angeles-based sample, the highest wage penalties occur for being either Black or a recent immigrant.

In column (b), we add our proxy for neighborhood poverty, HPOVPCT. The variable is negatively signed and highly significant and the adjusted R-squared improves with its inclusion. Note that while the coefficients for the human capital variables remain roughly the same, the coefficients for the social markers of race and immigration drop, with the coefficient for AFAM dropping most, this suggests that at least part of what might be viewed as straightforward racial discrimination may also be neighborhood effects. The coefficient on HPOVPCT itself suggests that a 1 percent increase in the poverty rate of one's neighbors lowers one's own salary by around one percent; for example, a move from the relatively poor South Vermont area of central L.A. to the suburban city of Glendale, neighborhoods which are roughly equidistant from downtown L.A, is as- 


\section{TABLE 3}

Wage Regressions Including Variables for Neighborhood Poverty and Average Travel Time

(Dependent variable $=$ LNWAGE)

\begin{tabular}{|c|c|c|c|c|}
\hline & $\begin{array}{c}\text { Basic wage } \\
\text { regression } \\
(3 a)\end{array}$ & $\begin{array}{c}\text { Regression w/ } \\
\text { HPOVPCT } \\
\text { (3b) }\end{array}$ & $\begin{array}{c}\text { Regression w/ } \\
\text { AVGTRHR } \\
\text { (3c) }\end{array}$ & $\begin{array}{c}\text { Regression w/ } \\
\text { HPOVPCT \& } \\
\text { AVGTRHR } \\
\text { (3d) }\end{array}$ \\
\hline \multirow[t]{2}{*}{ YEARSCH } & 0.065 & 0.061 & 0.065 & 0.061 \\
\hline & $(33.385) * * *$ & $(31.410)^{* * *}$ & $(33.174)^{* * *}$ & $(31.312)^{* * *}$ \\
\hline \multirow[t]{2}{*}{ EXPWORK } & 0.036 & 0.036 & 0.036 & 0.036 \\
\hline & $(22.145) * * *$ & $(21.933)^{* * *}$ & $(22.232)^{* * *}$ & $(21.987)^{* * *}$ \\
\hline \multirow[t]{2}{*}{ EXPWRKSQ } & -0.001 & -0.001 & -0.001 & -0.001 \\
\hline & $(-17.574) * * *$ & $(-17.168)^{* * *}$ & $(-17.697)^{* * *}$ & $(-17.245)^{* * *}$ \\
\hline \multirow[t]{2}{*}{ MARRIED } & 0.169 & 0.156 & 0.172 & 0.158 \\
\hline & $(13.466) * * *$ & $(12.493)^{* * *}$ & $(13.628)^{* * *}$ & $(12.601)^{* * *}$ \\
\hline \multirow[t]{2}{*}{ ENGLIM } & -0.185 & -0.171 & -0.187 & -0.172 \\
\hline & $(-8.568) * * *$ & $(-7.970) * * *$ & $(-8.641)^{* * *}$ & $(-8.024) * * *$ \\
\hline \multirow[t]{2}{*}{ IMM70S } & -0.151 & -0.133 & -0.150 & -0.133 \\
\hline & $(-8.309) * * *$ & $(-7 .-387)^{* * *}$ & $(-8.299) * * *$ & $(-7.396)^{* * *}$ \\
\hline \multirow[t]{2}{*}{ IMM80S } & -0.313 & -0.294 & -0.313 & -0.294 \\
\hline & $(-16.975)^{* * *}$ & $(-16.025)^{* * *}$ & $(-16.950)^{* * *}$ & $(-16.025)^{* * *}$ \\
\hline \multirow[t]{2}{*}{ AFAM } & -0.248 & -0.166 & -0.246 & -0.167 \\
\hline & $(-15.344) * * *$ & $(-9.763)^{* * *}$ & $(-15.276)^{* * *}$ & $(-9.802) * * *$ \\
\hline \multirow[t]{2}{*}{ LATINO } & -0.180 & -0.141 & -0.181 & -0.142 \\
\hline & $(-9.852) * * *$ & $(-7.664) * * *$ & $(-9.922) * * *$ & $(-7.739) * * *$ \\
\hline \multirow[t]{2}{*}{ ASIAN } & -0.112 & -0.096 & -0.115 & -0.098 \\
\hline & $(-6.393) * * *$ & $(-5.491)^{* * *}$ & $(-6.537)^{* * *}$ & $(-5.594) * * *$ \\
\hline \multirow[t]{2}{*}{ HPOVPCT } & & -0.011 & & -0.011 \\
\hline & & $(-14.009)^{* * *}$ & & $(-13.701)^{* * *}$ \\
\hline \multirow[t]{2}{*}{ AVGTRHR } & & & -0.502 & -0.314 \\
\hline & & & $(-3.716)^{* * *}$ & $(-2.330)^{* *}$ \\
\hline Adjusted R2 & 0.335 & 0.346 & 0.336 & 0.347 \\
\hline Number of obs. & 11,110 & 11,110 & 11,110 & 11,110 \\
\hline F-value & $560.0 * * *$ & $535.9 * * *$ & $510.9 * * *$ & $491.8 * * *$ \\
\hline *** -significant at & level & & & \\
\hline $\begin{array}{ll}* * & \text {-significant at } \\
* & \text {-significant at }\end{array}$ & $\begin{array}{l}.05 \text { level } \\
.10 \text { level }\end{array}$ & & & \\
\hline
\end{tabular}


sociated with a 20 percent. increase in income for a person with exactly the same human capital and demographic characteristics. This aggregate analysis squares nicely with the reported income increases experienced by public-housing residents relocating under Chicago's Gautreaux program. ${ }^{17}$

Column (c) drops HPOVPCT, a network quality measure, in favor of AVGTRHR, a spatial mismatch variable similar to that used in Ihlanfeldt and Sjoquist (1990b). ${ }^{18}$ While this variable is appropriately signed (a further distance lowers the wage) and significant, the explanatory power of the regression falls to that of column (a) and the various coefficients for other variables similarly return to their "original" values. The relative unimportance of AVGTRHR is further demonstrated when, in column (d), we combine it with HPOVPCT: the coefficients and explanatory power mirror that obtained when HPOVPCT is entered alone, while the T-score for the spatial variable is less than one-third of that for any other measure in the regression and exhibits a two-tail significance of only .05. Moreover, while the "network" impact on wages for living in South Vermont rather than Glendale remains at about 20 percent, as reported above, multiplication of the distance differential by the coefficient on AVGTRHR reveals that the cost of the spatial mismatch for the same two comparison neighborhoods is only about 2 percent. This pattern suggests that what matters is not physical, but social distance from high-wage networks, an entirely sensible notion when one considers the long-distance commutes of many successful middle-class workers in Los Angeles County. As a result, we focus most of the rest of our analysis on HPOVPCT, re-introducing AVGTRHR for a few selective comparisons.

Does this "network effect" hold across different ethnic groups? Table 4 examines this question in two panels. The left hand side, columns (a) through (d), runs the regression from (b) in Table 3 for our four main ethnic groups. The righthand panel, columns (e) through (h), once again breaks the sample into the main ethnic groups. Here, however, we replace HPOVPCT with ETHHOODPOV, the poverty rate for an individual's same ethnic group in his particular neighborhood area. The idea here is that networks are partly structured by social discrimination and not simply location; Anglo yuppies gentrifying a central city may be less affected by proximate Black poverty, while Latino and Asian immigrants may have quite distinct social/job networks in a location of residence shared with a variety of other ethnic groups.

Turning to the results, we first note that the "base" regressions are slightly different for individual ethnic groups: we assume that limited English ability and recent immigration are relevant for Asians and Latinos, but generally unimportant for Anglos and African-Americans. Starting with (a) through (d), HPOVPCT is highly significant in all the regressions, with the highest coefficient values occurring for Anglos, then Asians, then Latinos, then African-Americans. The regres- 


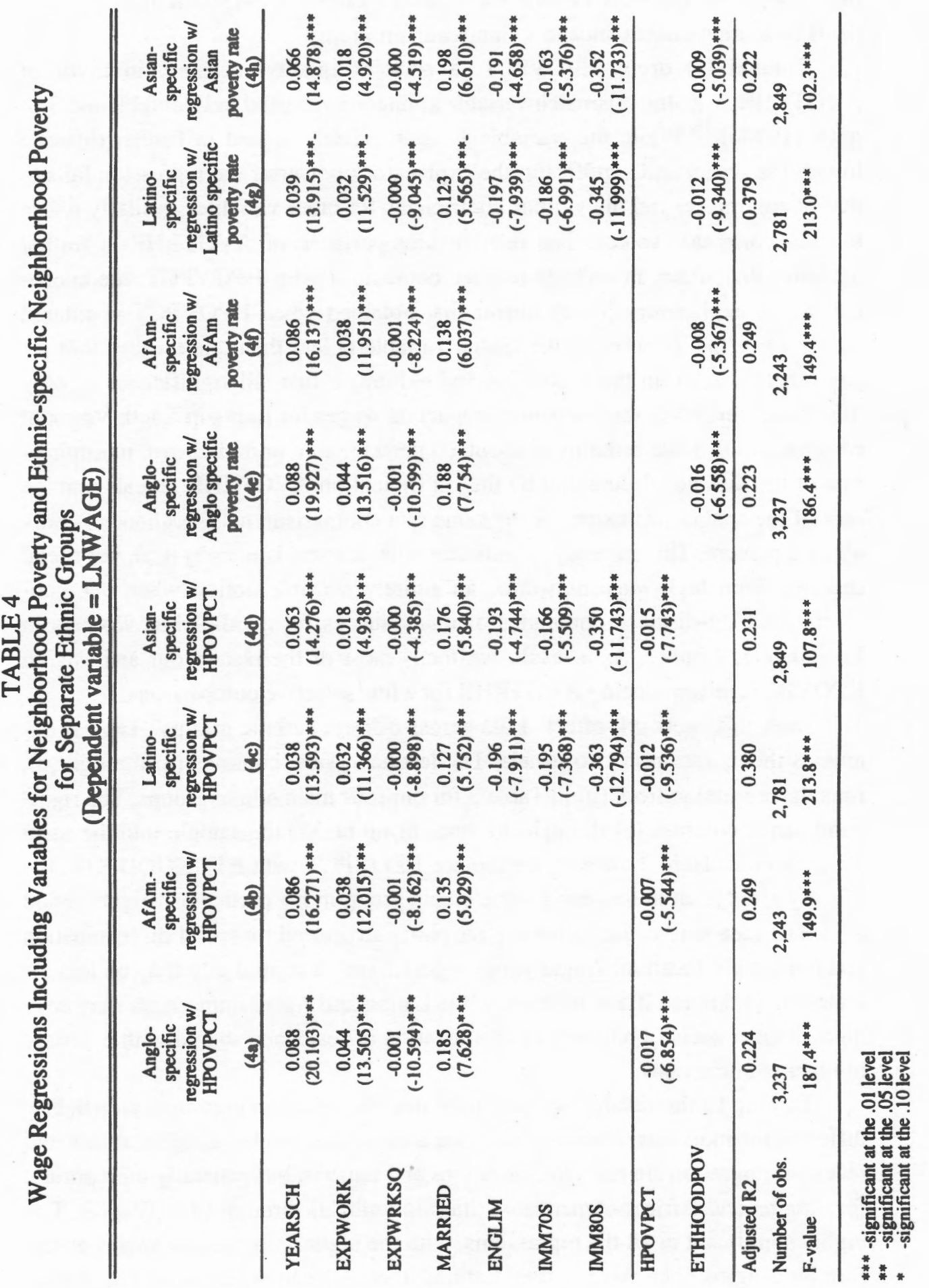


sion for Latinos yields the highest explanatory power and the highest jump in adjusted R-squared of any ethnic group for the addition of a neighborhood variable (base wage regressions for each ethnic group which did not include a neighborhood factor were run, but are not reported here). Columns (d) through (g) tell the story for ethnic-specific neighborhood poverty rates. ${ }^{19}$ As it turns out, for Anglos, Latinos, and African-Americans, the effects are the same using the ethnic-specific poverty rate as for using the overall neighborhood poverty rate; Asians, however, feel a larger negative impact from general neighborhood poverty than from the poverty rate of their own ethnic group in that neighborhood. ${ }^{20}$

Table 5 reintroduces the dimension of space by looking at the effects of individual commuting (versus the average travel from the PUMA neighborhood). The key variable here is TRAVHRS, the hours (or parts of hours) an individual spends making his/her way to work. ${ }^{21}$ We ran our wage regressions for all commuters and for those using "slow" and "fast" means of transport, with the former defined in the L.A. context as buses, streetcars, subways or elevated trains, the railroad, ferryboats, bicycles, walking, and "other methods," and the latter as including cars, trucks, vans, motorcycles, and taxicabs. As it turns out, "slow" commuters, comprising less than 7 percent of the sample, actually obtain a negative (albeit insignificant) return on their commuting time, a result which speaks volumes about the inefficiencies of public transportation in Los Angeles. We therefore decided to stick with and present the results for "fast" commuters. As can be seen in Table 5, those workers see a 5.2 percent increase in their hourly wage for each hour of their generally automotive morning commute, with the return rising to 7 percent if we control for spatial mismatch by reintroducing AVGTRHR. $^{22}$

It is, of course, unsurprising that commuting yields a return; if it did not, there would be little reason to spend time in traffic. For our analysis of neighborhood effects, what is more important is whether there is a differential return for those exiting poorer neighborhoods. To look at this question, we constructed an interaction variable in which we essentially separate out travel time for those departing high poverty neighborhoods (HIPOVTR) and those departing from low to medium poverty neighborhoods (LOMEPVTR), with the dividing line set at a 20 percent household poverty rate. ${ }^{23}$ A fascinating outcome emerges: the return for commuting in terms of the increase in hourly wage is four times greater when one departs from a poor neighborhood, with the return for commuting once again increasing if we control for spatial mismatch with AVGTRHR. It seems that there are significant gains to be made by gaining access to job networks that are far from one's own poverty-stricken neighborhoods.

While we offered results suggesting that traveling out of a poor neighborhood yields a high return, this it could be because our "high-poverty" commuters 
TABLE 5

Wage Regressions Exploring the Effects of Commuting (Dependent variable $=$ LNWAGE)

\begin{tabular}{|c|c|c|c|c|}
\hline \multicolumn{4}{|c|}{ Fast" Commuters Only } & \multirow[b]{2}{*}{$\begin{array}{c}\text { Regression w/ } \\
\text { HPOVPCT, } \\
\text { TRAVHRS, } \\
\text { HIPOVTR \& } \\
\text { LOMEPVTR } \\
\text { (5d) }\end{array}$} \\
\hline & $\begin{array}{c}\text { Regression w/ } \\
\text { HPOVPCT } \\
\text { \& TRAVHRS } \\
\text { (5a) }\end{array}$ & $\begin{array}{c}\text { Regression w/ } \\
\text { HPOVPCT, } \\
\text { TRAVHRS } \\
\text { \& AVGTRHR } \\
\text { (5b) }\end{array}$ & $\begin{array}{c}\text { Regression w/ } \\
\text { HPOVPCT, } \\
\text { HIPOVTR \& } \\
\text { LOMEPVTR } \\
\text { (5c) }\end{array}$ & \\
\hline \multirow[t]{2}{*}{ YEARSCH } & 0.062 & 0.062 & 0.062 & 0.062 \\
\hline & $-30.080 * * *$ & $-29.933 * * *$ & $-30.095 * * *$ & $-29.932 * * *$ \\
\hline \multirow[t]{2}{*}{ EXPWORK } & 0.035 & 0.035 & 0.035 & 0.035 \\
\hline & $-19.873 * * *$ & $-19.960 * * *$ & $-19.857 * * *$ & $-19.957 * * *$ \\
\hline \multirow[t]{2}{*}{ EXPWRKSQ } & -0.001 & -0.001 & -0.001 & 0.001 \\
\hline & $(-15.088)^{* * *}$ & $(-15.202)^{* * *}$ & $(-15.086)^{* * *}$ & $(-15.220)^{* * *}$ \\
\hline \multirow[t]{2}{*}{ MARRIED } & 0.146 & 0.148 & 0.146 & 0.149 \\
\hline & $-11.174 * * *$ & $-11.305 * * *$ & $-11.210 * * *$ & $-11.371 * * *$ \\
\hline \multirow[t]{2}{*}{ ENGLIM } & -0.175 & -0.177 & -0.175 & -0.177 \\
\hline & $(-7.610)^{* * *}$ & $(-7.681)^{* * *}$ & $(-7.616)^{* * *}$ & $(-7.700)^{* * *}$ \\
\hline \multirow[t]{2}{*}{ IMM70S } & -0.122 & -0.122 & -0.122 & -0.122 \\
\hline & $(-6.657) * * *$ & $(-6.663)^{* * *}$ & $(-6.643)^{* * *}$ & $(-6.647)^{* * *}$ \\
\hline \multirow[t]{2}{*}{ IMM80S } & -0.292 & -0.292 & -0.293 & -0.292 \\
\hline & $(-15.273) * * *$ & $(-15.262)^{* * *}$ & $(-15.281)^{* * *}$ & $(-15.271)^{* * *}$ \\
\hline \multirow[t]{2}{*}{ AFAM } & -0.159 & -0.160 & -0.160 & -0.161 \\
\hline & $(-8.975) * * *$ & $(-9.033)^{* * *}$ & $(-9.031)^{* * *}$ & $(-9.111)^{* * *}$ \\
\hline \multirow[t]{2}{*}{ LATINO } & -0.146 & -0.147 & -0.144 & -0.146 \\
\hline & $(-7.754) * * *$ & $(-7.847)^{* * *}$ & $(-7.696)^{* * *}$ & $(-7.794)^{* * *}$ \\
\hline \multirow[t]{2}{*}{ ASIAN } & -0.102 & -0.105 & -0.099 & -0.102 \\
\hline & $(-5.751)^{* * *}$ & $(-5.911)^{* * *}$ & $(-5.584)^{* * *}$ & $(-5.739)^{* * *}$ \\
\hline \multirow[t]{2}{*}{ HPOVPCT } & -0.010 & -0.010 & -0.012 & -0.013 \\
\hline & $(-12.116)^{* * *}$ & $(-11.800)^{* * *}$ & $(-10.893)^{* * *}$ & $(-11.034)^{* * *}$ \\
\hline \multirow[t]{2}{*}{ TRAVHRS } & 0.058 & 0.070 & & \\
\hline & $-2.974 * * *$ & $-3.546 * * *$ & & \\
\hline \multirow[t]{2}{*}{ HIPOVTR } & & & $0.162 * * *$ & 0.199 \\
\hline & & & (3.708) & $(4.447)^{* * *}$ \\
\hline \multirow[t]{2}{*}{ LOMEPOVTR } & & & $0.044 * *$ & 0.056 \\
\hline & & & $(2.227)$ & $(2.771)^{* * *}$ \\
\hline \multirow[t]{2}{*}{ AVGTRHR } & & -0.449 & & -0.521 \\
\hline & & $(-3.194)^{* * *}$ & & $(-3.664)^{* * *}$ \\
\hline Adjusted R2 & 0.338 & 0.338 & 0.338 & 0.339 \\
\hline Number of obs. & 9,670 & 9,670 & 9,670 & 9,670 \\
\hline F-value & $412.0 * * *$ & $381.4^{* * *}$ & $381.1 * * *$ & $355.3^{* * *}$ \\
\hline
\end{tabular}

**** -significant at the .01 level

** -significant at the .05 level

* - significant at the .10 level 
TABLE 6

Wage Regressions Exploring the "Economic Direction" of Commuting (Dependent variable $=$ LNWAGE)

\begin{tabular}{|c|c|c|c|}
\hline & $\begin{array}{l}\text { Regression w/ } \\
\text { POVDIF1 \& } \\
\text { HPOVPCT }\end{array}$ & $\begin{array}{l}\text { Regression w/ } \\
\text { POVDIF2 \& } \\
\text { HPOVPCT }\end{array}$ & $\begin{array}{l}\text { Regression w/ } \\
\text { POVDIF1 \& } \\
\text { HPOVPCT } \\
\text { selecting out } \\
6400 \text { s \& } 6500 \text { s } \\
\text { (6) }\end{array}$ \\
\hline \multirow[t]{2}{*}{ YEARSCH } & 0.061 & 0.061 & 0.063 \\
\hline & $-29.648 * * *$ & $-29.736 * * *$ & $-14.193 * * *$ \\
\hline \multirow[t]{2}{*}{ EXPWORK } & 0.036 & 0.036 & 0.042 \\
\hline & $-20.806 * * *$ & $-20.827 * * *$ & $-10.766 * * *$ \\
\hline \multirow[t]{2}{*}{ EXPWRKSQ } & -0.001 & -0.001 & -0.001 \\
\hline & $(-16.395)^{* * *}$ & $(-16.413)^{* * *}$ & $(-8.318) * * *$ \\
\hline \multirow[t]{2}{*}{ MARRIED } & 0.152 & 0.152 & 0.133 \\
\hline & $-11.533 * * *$ & $-11.539 * * *$ & $-4.641 * * *$ \\
\hline \multirow[t]{2}{*}{ ENGLIM } & -0.173 & -0.172 & -0.165 \\
\hline & $(-7.663) * * *$ & $(-7.648) * * *$ & $(-3.244) * * *$ \\
\hline \multirow[t]{2}{*}{ IMM70S } & -0.144 & -0.144 & -0.133 \\
\hline & $(-7.612) * * *$ & $(-7.611) * * *$ & $(-3.182) * * *$ \\
\hline \multirow[t]{2}{*}{ IMM80S } & -0.301 & -0.300 & -0.264 \\
\hline & $(-15.584) * * *$ & $(-15.579) * * *$ & $(-6.163) * * *$ \\
\hline \multirow[t]{2}{*}{ AFAM } & -0.155 & -0.154 & -0.164 \\
\hline & $(-8.604) * * *$ & $(-8.589) * * *$ & $(-4.280) * * *$ \\
\hline \multirow[t]{2}{*}{ LATINO } & -0.143 & -0.143 & -0.079 \\
\hline & $(-7.422) * * *$ & $(-7.404) * * *$ & $(-1.875)^{*}$ \\
\hline \multirow[t]{2}{*}{ ASIAN } & -0.085 & -0.085 & -0.083 \\
\hline & $(-4.628) * * *$ & $(-4.629) * * *$ & $(-2.031)^{* *}$ \\
\hline \multirow[t]{2}{*}{ HPOVPCT } & -0.011 & -0.012 & -0.019 \\
\hline & $(-7.252)^{* * *}$ & $(-13.012)^{* * *}$ & $(-5.937)^{* * *}$ \\
\hline \multirow[t]{2}{*}{ POVDIF1 } & -0.001 & & 0.006 \\
\hline & $(-0.589)$ & & $(2.508) * *$ \\
\hline \multirow[t]{2}{*}{ POVDIF2 } & & 0.002 & \\
\hline & & (1.041) & \\
\hline Adjusted R2 & 0.352 & 0.352 & 0.336 \\
\hline Number of obs. & 9,811 & 9,811 & 2,064 \\
\hline F-value & $444.8 * * *$ & $444.9 * * *$ & $87.8 * * *$ \\
\hline
\end{tabular}

*** -significant at the .01 level

** -significant at the .05 level

* - significant at the .10 level 
are simply driving to close job locations (due to social or network limits on their job search); in this case, the return on commuting seems to be high only because the commute is so short. One way to tease out the effectiveness of commuting to a high "quality" neighborhood and its network would be to compare the general economic characteristics of neighborhood of residence and neighborhood of work.

Fortunately, the PUMS database includes a variable indicating the PUMA in which one works. Unfortunately, this place-of-work PUMA, termed POWA, is much broader in its definition than the residence PUMA. Specifically, anyone working in PUMAs 6401 to 6424 is simply recorded as working in the City of Los Angeles (6400), a unit of well over 3.4 million people, which therefore effectively "erases" the neighborhood detail so central to our analysis. A similar pattern occurs for the areas of L.A. County that are designated with 6501 to 6521 ; if one works in this similarly large area of nearly 3.5 million residents, POWA is recorded as 6500 and it is impossible to differentiate between neighborhoods. Only PUMAs 5200 to 6300 , and 6600 are designated both as residence PUMAs and specific POWAs.

Due to this unfortunate lack of detail, we tried three different regressions. In the first, we entered POVDIF1, a variable comparing the poverty rate of one's PUMA to the poverty rate of one's POWA; a positive difference was supposed to have a positive effect on wages (i.e., one is working in a richer neighborhood and hence improving one's network). In this regression, we include all of L.A. County, including the City and those County areas (6401 to 6521) for which we have only, say, the broad designation of L.A. City as a category (note that the sample size is reduced from that in Table 3, since once again we can test only for those working this year). This poverty difference measure is too broad to capture neighborhood "quality," which is, perhaps unsurprisingly, not significant. In column (b), we decided to create a symmetry in the poverty difference measure (here titled POVDIF2) by assigning the L.A. City poverty rate to anyone living in an L.A. City neighborhood and the aggregate County poverty rate (for those PUMAs 6501 to 6251 ) to residents of those County neighborhoods/cities. This once again misses most of the finer neighborhood PUMA distinctions we were seeking to test; in this run, the variable has the expected positive sign, but is also not significant.

It is only in the third run (column (c)) that the variable is truly measuring what we hoped-the difference in economic conditions in narrowly defined residence and work neighborhoods. In order to do that, however, we were forced to drop all the "broad" 6400 and 6500 POWAs (although we are able to use these areas on the residence side, since on this side we do have specific neighborhoods and their poverty rates). The sample is reduced to only one-fifth of its former size, 
but the results of this truly appropriate regression are highly comforting for our network hypothesis: controlling for one's resident poverty rate (with HPOVPCT), working in a neighborhood where the poverty rate is 1 percent less will raise wages by 0.6 percent. ${ }^{24}$ Returning to our South Vermont-Glendale comparison, while moving to the latter would certainly have an even larger positive effect, working there is associated with an 11 percent improvement in one's hourly wage, again holding all other human capital and demographic characteristics constant.

What about the possibility that our results reflect not the impact of neighborhoods on wages, but of wages on neighborhood location? While our practice of assuming the exogeneity of neighborhood follows the practice of earlier articles, we tackle this issue in two ways. First, we examine individuals who live in households with a long history of residence in the PUMA neighborhood. ${ }^{25}$ Second, we attempt to reestimate the various regressions using a two-stage least squares approach.

In Table 7, we report on the first procedure. The two panels of Table 7 display the results for regressions, using only those whose households were in place since either 1983 or 1978 . Each panel tests first only for neighborhood effects (HPOVPCT) and then for commuting from poor and non-poor neighborhoods for those using rapid forms of transport. The results for all runs are nearly identical in signs, significance, and coefficient values to the results obtained with full sample; most significant is that HPOVPCT has only a slightly more modest negative impact on individual wages than in the regressions including more recent residents. $^{26}$

For the two-stage least squares approach, we borrowed from the locational research of Logan and Alba (1993) to devise a simple underlying model of how individuals might allocate themselves into our 58 different PUMAs. In addition to wages, the key variables were housing costs, own ethnicity and neighbor ethnicity, immigrant presence (since this might signal a "port of entry" and hence attract other immigrants), and length of previous residence in the same PUMA (i.e., "residential stability"). ${ }^{27}$ This yielded the following instruments for our wage regression: HOUSECOSTS, the log of total monthly housing costs for the household of residence; HOMEOWN, a dummy variable equal to one if the household of residence is owned; YRMOVED, a variable which ranges from 1 to 6 over various bands of years, with a higher value indicating that the household was consituted at this residence in an earlier era, and a series of neighborhood ethnic characteristics; ANGLOPCT; AFAMPCT; LATINOPCT; ASIANPCT; and IMM80PCT, which attempt to capture the attracting or repelling factors that neighborhood ethnicity and immigrant presence might have on the location decision of particular individuals. ${ }^{28}$ 
TABLE 7

Wage Regressions with Neighborhood Poverty and Commute Measures for Long-term Residents

(Dependent variable $=$ LNWAGE)

\begin{tabular}{|c|c|c|c|c|}
\hline & \multicolumn{2}{|c|}{$\begin{array}{l}\text { Head of Household Moved } \\
\text { into Residence before } 1984\end{array}$} & \multicolumn{2}{|c|}{$\begin{array}{l}\text { Head of Household Moved } \\
\text { into Residence before } 1979\end{array}$} \\
\hline & $\begin{array}{c}\text { Regression w/ } \\
\text { HPOVPCT } \\
\text { (7a) }\end{array}$ & $\begin{array}{l}\text { Regression w/ } \\
\text { HPOVPCT, } \\
\text { HIPOVTR \& } \\
\text { LOMEPVTR } \\
(7 \mathrm{~b})\end{array}$ & $\begin{array}{c}\text { Regression w/ } \\
\text { Regression w/ } \\
\text { HPOVPCT } \\
(7 c)\end{array}$ & $\begin{array}{l}\text { HPOVPCT, } \\
\text { HIPOVTR \& } \\
\text { LOMEPVTR } \\
\text { (7d) }\end{array}$ \\
\hline$\overline{\text { YEARSCH }}$ & $\begin{array}{c}0.067 \\
(20.257) * * *\end{array}$ & $\begin{array}{c}0.067 \\
(20.374)^{* * *}\end{array}$ & $\begin{array}{c}0.070 \\
(16.118)^{* * * *}\end{array}$ & $\begin{array}{c}0.070 \\
(16.256)^{* * *}\end{array}$ \\
\hline EXPWORK & $\begin{array}{c}0.035 \\
-13.350^{* * *}\end{array}$ & $\begin{array}{c}0.036 \\
-13.348^{* * *}\end{array}$ & $\begin{array}{c}0.037 \\
-11.334^{* * *}\end{array}$ & $\begin{array}{c}0.036 \\
-10.723 * * *\end{array}$ \\
\hline EXPWRKSQ & $\begin{array}{c}-0.000 \\
(-10.867)^{* * *}\end{array}$ & $\begin{array}{c}-0.001 \\
(-10.708)^{* * *}\end{array}$ & $\begin{array}{c}-0.001 \\
(-9.207)^{* * *}\end{array}$ & $\begin{array}{l}-0.000 \\
(-8.502)^{* * *}\end{array}$ \\
\hline MARRIED & $\begin{array}{l}0.184 \\
-8.474 * * *\end{array}$ & $\begin{array}{l}0.183 \\
-8.314^{* * *}\end{array}$ & $\begin{array}{l}0.189 \\
-6.511^{* * *}\end{array}$ & $\begin{array}{l}0.196 \\
-6.697^{* * *}\end{array}$ \\
\hline ENGLIM & $\begin{array}{l}-0.130 \\
(-3.331)^{* * *}\end{array}$ & $\begin{array}{c}-0.154 \\
(-3.841)^{* * *}\end{array}$ & $\begin{array}{c}-0.130 \\
(-2.245)^{* *}\end{array}$ & $\begin{array}{c}-0.164 \\
(-2.821)^{* * *}\end{array}$ \\
\hline IMM70S & $\begin{array}{l}-0.157 \\
(-5.461)^{* * *}\end{array}$ & $\begin{array}{l}-0.140 \\
(-4.921)^{* * *}\end{array}$ & $\begin{array}{c}-0.142 \\
(-3.399)^{* * *}\end{array}$ & $\begin{array}{c}-0.134 \\
(-3.245)^{* * *}\end{array}$ \\
\hline IMM80S & $\begin{array}{l}-0.299 \\
(-7.729)^{* * *}\end{array}$ & $\begin{array}{l}-0.285 \\
(-7.174)^{* * *}\end{array}$ & $\begin{array}{l}-0.285 \\
(-3.648)^{* * *}\end{array}$ & $\begin{array}{l}-0.278 \\
(-3.419)^{* * *}\end{array}$ \\
\hline AFAM & $\begin{array}{l}-0.118 \\
(-4.382) * * *\end{array}$ & $\begin{array}{l}-0.125 \\
(-4.620)^{* * *}\end{array}$ & $\begin{array}{l}-0.127 \\
(-3.782)^{* * *}\end{array}$ & $\begin{array}{c}-0.139 \\
(-4.154)^{* * *}\end{array}$ \\
\hline LATINO & $\begin{array}{c}-0.108 \\
(-3.789) * * *\end{array}$ & $\begin{array}{l}-0.117 \\
(-4.137)^{* * *}\end{array}$ & $\begin{array}{l}-0.107 \\
(-3.066)^{* * *}\end{array}$ & $\begin{array}{c}-0.115 \\
(-3.357)^{* * *}\end{array}$ \\
\hline ASIAN & $\begin{array}{l}-0.093 \\
(-3.512)^{* * *}\end{array}$ & $\begin{array}{l}-0.094 \\
(-3.599)^{* * *}\end{array}$ & $\begin{array}{c}-0.098 \\
(-2.908)^{* * *}\end{array}$ & $\begin{array}{c}-0.099 \\
(-2.986)^{* * *}\end{array}$ \\
\hline HPOVPCT & $\begin{array}{c}-0.010 \\
(-8.316)^{* * *}\end{array}$ & $\begin{array}{c}-0.011 \\
(-6.275)^{* * *}\end{array}$ & $\begin{array}{c}-0.008 \\
(-5.243)^{* * *}\end{array}$ & $\begin{array}{c}-0.010 \\
(-4.482)^{* * *}\end{array}$ \\
\hline HIPOVTR & & $\begin{array}{c}0.114 \\
(1.850)^{*}\end{array}$ & & $\begin{array}{c}0.160 \\
(2.072)^{* *}\end{array}$ \\
\hline LOMEPOVTR & & $\begin{array}{r}0.042 \\
-1.302\end{array}$ & & $\begin{array}{r}0.046 \\
-1.137\end{array}$ \\
\hline Adjusted R2 & 0.331 & 0.344 & 0.301 & 0.321 \\
\hline Number of obs. & 4,490 & 3,964 & 2,870 & 2,532 \\
\hline F-value & $202.7 * * *$ & $160.7 * * *$ & $113.4^{* * *}$ & $93.1^{* * *}$ \\
\hline
\end{tabular}

*** -significant at the .01 level

** -significant at the .05 level

* - significant at the .10 level 


\section{TABLE 8}

Various Wage Regressions Done Using Two-stage Least Squares Method (Dependent variable $=$ LNWAGE)

\begin{tabular}{|c|c|c|c|c|c|}
\hline & $\begin{array}{c}\text { Regression w/ } \\
\text { HPOVPCT } \\
\text { (8a) }\end{array}$ & $\begin{array}{c}\text { Regression w/ } \\
\text { HPOVPCT \& } \\
\text { AVGTRHR } \\
\text { (8b) }\end{array}$ & $\begin{array}{l}\text { Regression w/ } \\
\text { HPOVPCT, } \\
\text { HIPOVTR \& } \\
\text { LOMEPVTR \& } \\
\text { (\&c) }\end{array}$ & $\begin{array}{c}\text { Regression w/ } \\
\text { HPOVPCT, } \\
\text { AVGTRHR, } \\
\text { HIPOVTR \& } \\
\text { LOMEPVTR } \\
\text { (\&d) }\end{array}$ & $\begin{array}{l}\text { Regression w/ } \\
\text { POVDIFF1 } \\
\text { (selecting out } \\
6400 \text { s and } \\
6500 \text { s) } \\
\text { (c) }\end{array}$ \\
\hline YEARSCH & $\begin{array}{c}0.059 \\
-30.528^{* * *}\end{array}$ & $\begin{array}{c}0.059 \\
-30.433 * * *\end{array}$ & $\begin{array}{c}0.061 \\
-37.144^{* * *}\end{array}$ & $\begin{array}{c}0.060 \\
-29.149 * * *\end{array}$ & $\begin{array}{c}0.059 \\
-13.733 * * *\end{array}$ \\
\hline EXPWORK & $\begin{array}{c}0.034 \\
-21.180^{* * *}\end{array}$ & $\begin{array}{c}0.034 \\
-21.225^{* * *}\end{array}$ & $\begin{array}{c}0.034 \\
-19.627^{* * *}\end{array}$ & $\begin{array}{c}0.035 \\
-19.727^{* * *}\end{array}$ & $\begin{array}{l}0.038 \\
-9.918 * * *\end{array}$ \\
\hline EXPWRKSQ & $\begin{array}{c}-0.001 \\
(-16.497)^{* * *}\end{array}$ & $\begin{array}{c}-0.001 \\
(-16.566)^{* * *}\end{array}$ & $\begin{array}{c}-0.001 \\
(-14.903)^{* * *}\end{array}$ & $\begin{array}{c}-0.001 \\
(-15.043)^{* * *}\end{array}$ & $\begin{array}{r}-0.001 \\
(-7.705)^{* * *}\end{array}$ \\
\hline MARRIED & $\begin{array}{c}0.153 \\
-12.290^{* * *}\end{array}$ & $\begin{array}{c}0.154 \\
-12.387 * * *\end{array}$ & $\begin{array}{c}0.145 \\
-11.027 * * *\end{array}$ & $\begin{array}{l}0.147 \\
-11.199 * * *\end{array}$ & $\begin{array}{l}0.128 \\
-4.667 * * *\end{array}$ \\
\hline ENGLIM & $\begin{array}{l}-0.170 \\
(-7.963)^{* * *}\end{array}$ & $\begin{array}{c}-0.171 \\
(-8.013)^{* * *}\end{array}$ & $\begin{array}{c}-0.173 \\
(-7.500) * * *\end{array}$ & $\begin{array}{c}-0.175 \\
(-7.591)^{* * *}\end{array}$ & $\begin{array}{c}-0.172 \\
(-3.555) * * * *\end{array}$ \\
\hline IMM70S & $\begin{array}{l}-0.128 \\
(-7.165)^{* * * *}\end{array}$ & $\begin{array}{c}-0.128 \\
(-7.174)^{* * *}\end{array}$ & $\begin{array}{l}-0.117 \\
(-6.332)^{* * *}\end{array}$ & $\begin{array}{l}-0.117 \\
(-6.343)^{* * *}\end{array}$ & $\begin{array}{c}-0.123 \\
(-3.076)\end{array}$ \\
\hline IMM80S & $\begin{array}{c}-0.292 \\
(-16.024)^{* * *}\end{array}$ & $\begin{array}{c}-0.292 \\
(-16.028)^{* * *}\end{array}$ & $\begin{array}{c}-0.288 \\
(-14.990)^{* * *}\end{array}$ & $\begin{array}{c}-0.288 \\
(-14.990)^{* * *}\end{array}$ & $\begin{array}{r}-0.269 \\
(-6.597)^{* * * *}\end{array}$ \\
\hline AFAM & $\begin{array}{c}-0.144 \\
(-8.310)^{* * *}\end{array}$ & $\begin{array}{c}-0.144 \\
(-8.339)^{* * *}\end{array}$ & $\begin{array}{c}-0.139 \\
(-7.704)^{* * *}\end{array}$ & $\begin{array}{c}-0.141 \\
(-7.818)^{* * *}\end{array}$ & $\begin{array}{c}-0.150 \\
(-4.009)^{* * *}\end{array}$ \\
\hline LATINO & $\begin{array}{l}-0.139 \\
(-7.587)^{* * *}\end{array}$ & $\begin{array}{c}-0.140 \\
(-7.665)^{* * *}\end{array}$ & $\begin{array}{l}-0.135 \\
(-7.114)^{* * *}\end{array}$ & $\begin{array}{c}-0.137 \\
(-7.253)^{* * *}\end{array}$ & $\begin{array}{c}-0.094 \\
(-2.306)^{* *}\end{array}$ \\
\hline ASIAN & $\begin{array}{l}-0.095 \\
-5.500^{* * *}\end{array}$ & $\begin{array}{l}-0.097 \\
(-5.605)^{* * *}\end{array}$ & $\begin{array}{c}-0.091 \\
(-5.121)^{* * *}\end{array}$ & $\begin{array}{c}-0.095 \\
(-5.316)^{* * *}\end{array}$ & $\begin{array}{c}-0.092 \\
(-2.375)^{* *}\end{array}$ \\
\hline HPOVPCT & $\begin{array}{c}-0.015 \\
(-15.793)^{* * *}\end{array}$ & $\begin{array}{c}-0.014 \\
(-15.541)^{* * *}\end{array}$ & $\begin{array}{c}-0.018 \\
(-12.670)^{* * *}\end{array}$ & $\begin{array}{c}-0.018 \\
(-12.716)^{* * *}\end{array}$ & $\begin{array}{c}-0.028 \\
(-6.821)^{* * *}\end{array}$ \\
\hline AVGTRHR & & $\begin{array}{c}-0.292 \\
(-2.175)^{* *}\end{array}$ & & $\begin{array}{c}-0.543 \\
(-3.805)^{* * *}\end{array}$ & \\
\hline HIPOVTR & & & $\begin{array}{l}0.276 \\
(5.838)^{* * *}\end{array}$ & $\begin{array}{c}0.311 \\
(6.441)^{* * *}\end{array}$ & \\
\hline LOMEPOVTRं & & & $\begin{array}{r}0.026 \\
(1.276)\end{array}$ & $\begin{array}{c}0.038 \\
(1.871)^{*}\end{array}$ & \\
\hline POVDIFF1 & & & & & $\begin{array}{c}0.011 \\
(3.985)^{* * *}\end{array}$ \\
\hline Adjusted R2 & 0.350 & 0.351 & 0.337 & 0.338 & 0.350 \\
\hline Number of obs. & 10,990 & 10,990 & 9,619 & 9,619 & 2,017 \\
\hline F-value & $545.8^{* * *}$ & $501.2^{* * *}$ & $382.3 * * *$ & $356.3 * * *$ & $93.8^{* * *}$ \\
\hline
\end{tabular}

*** -significant at the .01 level

* - significant at the .05 level

* -significant at the .10 level 
The results of this two-stage least squares approach are listed in Table 8 for various key regressions, including tests for the effects of neighborhood poverty, spatial mismatch, commuting from low and high poverty neighborhoods (with and without a control for spatial mismatch), and the economic direction of commuting. Note that the number of observations is lower than in the parallel OLS runs. This is because we were forced to drop a few individuals for whom housing costs could not be calculated. ${ }^{29}$ The overall results are quite congenial: significance levels are high, the coefficients on the human capital and ethnicity variables remain virtually the same, and HPOVPCT continues to "dominate" AVGTRHR as an explanatory variable.

Taken together, the overall pattern of results squares with our notion that neighbors and networks matter. Controlling for the usual human capital and social variables, living in a poorer neighborhood tends to dampen wages-with the result holding for all ethnic groups and remaining generally the same if we use only the poverty rate for one's own ethnic group in the specific neighborhood. Moreover, "social distance," i.e., networks, seems to matter more than spatial distance. Commuting yields the expected increase in income and the returns are particularly high for those exiting poorer neighborhoods and attaching to job networks in higher income neighborhoods. Finally, the results hold under both OLS and twostage least squares specifications.

\section{v. CONCLUSIONS}

Policy-makers have long been concerned about helping the urban poor improve their economic outcomes. While serious action on this issue has waxed and waned depending on the party in power and the bureaucrats in charge, the implicit strategy for economic betterment has often been "place-based"; that is, the focus has often been on bringing jobs to the community via empowerment and enterprise zones, targeted block grants, housing developments, and the like.

This paper has explored the impact of place on earnings. Bringing together the characteristics of relatively narrow neighborhoods (at least by the standards of the literature) and individual observations on human capital and social "markers" (i.e., race and ethnicity), our regression results suggest that place is indeed a determinant of economic outcomes: living in a poor neighborhood dampens your expected wage, while commuting out raises it.

These results, however, may offer both support for, and warnings against, place-based anti-poverty strategies. On the one hand, economic development in a particular area can have the "spillover" effect of raising local incomes and hence improving networks. As one referee contended, this may be the only way to alleviate the effects of poor networks in the long run. On the other hand, it is pos- 
sible that such area-specific development can take place without actually involving significant hiring of neighborhood residents. In this case, resident poverty remains, the "quality" of resident job networks are not enhanced, and resident access to well-paying jobs improves little, if at all.

One way out of this dilemma is to focus on "people-based" strategies which seek to equip poor individuals with skills to take jobs wherever they might exist in the regional labor market. Note, however, that the results here suggest that skills are not enough: controlling for the relevant human capital variables, poor residents still land worse jobs. In this regard, job training programs might usefully incorporate policies to create "substitute" job networks via intense counseling, computer information systems, direct ties to employers, mobility enhancement, and the like. There remains, of course, a crucial role for place-based approaches which focus on improving housing and neighborhood amenities (such as small business), designed in part to insure that the enhanced mobility of neighborhood residents does not result in an exodus of successful individuals from the neighborhoods whose networks they can improve.

Still, a shift in policy focus toward mobility and network-building may be useful, and it is certainly consistent with new attempts to place poverty and inequality in the context of regional strategies-i.e., the increasingly popular notion that poorer residents will lose out unless they are networked with the emerging industries in a broader geographic area (Cisneros 1995). If, in short, neighbors matter, then we must all be each others' neighbors if we do not wish to see further decline in the fortunes of inner city residents. With such a new value and policy framework for public action, perhaps we can begin to reverse the damage of the past and pay real attention to improving the lot of the poor.

\section{ENDNOTES}

1. For more on the Gautreaux Program, see Popkin, Rosenbaum, and Meaden (1993).

2. Also, wages are likely to be affected by the same neighborhood variables that determine employment likelihoods for members of the so-called underclass, and so this is a more inclusive dependent variable.

3. Wilson (1987) also stresses the role of a "skill mismatch," but we focus on the geographic dimension in this paper. Skill levels are controlled for in our regression analysis via the use of various human capital characteristics.

4. Most of the literature fails to note the sort of address-signaling mechanism sketched out here (for an exception, see Kirschenmann and Necker- 
man 1991, pp. 215-217), but it would also seem to be an important part of the potential neighborhood effect.

5. This employer side (reduced information costs) is not stressed by O'Regan (1993) but would also seem to be important. For more on employer bias in hiring, see Kirschenmann and Neckerman (1991).

6. The pooling process also introduces complications if the nature of labor market relations between city and suburb is different by area of the United States.

7. Ihlanfeldt and Sjoquist (1990b) do employ finer geographical division, particularly in their look at the employment prospects for Philadelphia youth, but the neighborhood areas defined for their Los Angeles regressions are fewer than those employed here and the main "neighborhood-level" variable they employ is average commuting time for comparable workers. Here, we focus on neighborhood poverty characteristics as a way of proxying network quality; we also use average commute time to control for spatial mismatch.

8. For example, the 1990 poverty rates in the industrial cities of Bell, Bell Gardens, and Huntington Park were a full eight percentage points above those of the City of Los Angeles, while poverty rates in El Monte, Rosemead, and several other San Gabriel Valley cities were about the same as in L.A. Moveover, better than half of the cities that comprise the County are "majority-minority," making the traditional White-minority city-suburb dichotomy less applicable.

9. A positive employment outcome is, on the other hand, consistent, depending on the associated income, with residence in a wide variety of neighborhoods. In that sort of regression, neighborhood quality may proxy for the income that determines location and so may turn out to be, at the very least, "polluted" in its sign and significance.

10. There are, of course, a range of studies also trying simply to predict location. McMillen and Singell (1992) demonstrate the presence of wage gradients, which can explain the positive correlations between work and residence locations. Logan and Alba (1993) examine the impact of the human capital variables of different racial/ethnic minorities on their locational outcomes.

11. STF1 is a 100 percent or population count, while STF3 is a 10 percent count, representing a different sample than that in PUMS. Drawing from these data sources lends more exogeneity to the measure of neighborhood impact than would be obtained by simply aggregating all the individuals in PUMS by residence in order to determine neighborhood measures. By contrast, Ihlanfeldt and Sjoquist (1990b) drew their travel time variable directly from PUMS itself.

12. While the actual educational attainment variable in the 1990 census is called "YEARSCH," the measure does not actually record the number of years of education. Rather, it offers a ranking, starting with no school, nursery school, and kindergarten, then going on to those who completed from 1st to 4th and from 5th 
to 8 th, then those who completed successive years of high school (9th, 10th, 11th, 12th), and finally ranks individuals by some college experience, an A.A. degree (and whether it is occupational or academic), and then a bachelor's, a master's, a professional, and a doctorate degree. We mapped these ordinal ranks into likely years in school to follow the usual years of education measure in the literature and this is what is termed YEARSCH in the text; we then used this years of education measure to calculate work experience as indicated in the text.

13. Anglos are non-Hispanic whites. The categories African-American and Asian also exclude any Hispanics who also identify themselves as Black or Asian-Pacific (a very small percentage in L.A. County). Non-Hispanic other race (about 0.6 percent of L.A. County) are dropped from the sample for lack of a clear ethnic identifier; Native Americans are dropped because they are a very small proportion of the County population.

14. In the actual county population figures, Anglos comprise 40.8 percent, African-Americans 10.5 percent, Latinos 37.8 percent, Asians 10.2 percent, and others 0.6 percent. To accomplish the sampling used here, we used the subsample code which is available by household directly in the PUMS data. The code runs between 0 and 99; the U.S. Census Bureau recommends that to obtain a one-tenth sample, for example, researchers should select every tenth household (rather than ten in a row) to avoid the "clumping" of observations. To choose our starting household for each ethnic group sample, we used a random number generator to determine a number between 0 and 99 and chose every tenth or fifth, etc., depending on the desired sample size.

15. We also tested for individual and family poverty rates with similar results. In addition, we tested an employment rate (the ratio of employed males to all males over sixteen) as a measure of the probability of a network connection to a "good" job; this variable performed well on its own, but competed with HPOVPCT for significance in a regression with both variables while adding nothing to the regression's explanatory power (adjusted $R^{2}$ ). Since the two variables are so similar in their outcomes, we followed a referee's advice and stuck with just HPOVPCT in our presentation here.

16. More specifically, TRAVHRS measures the amount of time, in portions of an hour, that it takes residents to commute to their places of work. This time includes time spent waiting for public transportation, picking up passengers in carpools, and time spent in other activities related to getting to work. This is a one-way commute, and thus does not take into account the amount of time it takes for the resident to travel back home from work; in general, we would assume that the return trip is of equal length, although the vagaries of L.A. traffic patterns may make this assumption heroic. 
17. See Popkin, Rosenbau, and Meaden (1993). Part of the income increase from that experiment occurred from an increased likelihood of employment postmove; here, our hypothetical calculations are for those who are already employed.

18. The key difference is that our average travel time measure, following the procedure used for HPOVPCT, is derived from STF data rather than PUMS. This allows for more exogeneity, but, due to the nature of reporting in the Summary Tape Files, means that we cannot get travel time for just those using the most rapid form of transportation (i.e., autos, motorcycles, etc.) but must use travel time for all travel modes. Ihlanfeldt and Sjoquist (1990b, p. 269), however, report that their own series of average travel time measures, derived from PUMS, included some measures that were "inclusive of all modes of travel and the results are robust with respect to alternative measures." This finding enhances our confidence in the more inclusive measure used here.

19. Due to data limitations in the PUMS, the ethnic-specific poverty rates are derived from persons, and not households, as with HPOVPCT. If we substitute HPOVPCT with the ratio of neighborhood persons in poverty in the allgroups equation, the comparative pattern discussed in the text-congruity between neighborhood and neighborhood/ethnic effects for all groups except Asians-holds even more tightly.

20. If AVGTRHR is included in these sort of regressions, it is negative and significant for Anglos, positive but highly insignificant for African-Americans, positive but insignificant for Latinos, and negative and marginally significant (.10 level) for Asians. The generally poor performance of this measure, particularly for the ethnic groups likely to dominate the central city population, again speaks to the weakness of the effects deriving from spatial mismatch and lends credence to our emphasis on networks or concentrated poverty.

21. Note that there is a reduction in the number of observations. The reason is that the Census collects employment status for this year but reports on wage earnings from last year. While this should not impact any of the previous regressions (since all of the human capital and race variables were still present the year before and hence played a role in the determination of wages), some of those in the wage regression were in fact unemployed in the current period and hence not commuting at the time of the survey. We therefore dropped this group from the sample for this set of regressions and also dropped those who reported that they were working at home.

This discussion may lead some readers to be concerned about our use of location in all of these regressions; after all, we have entered this year's location as a determinant of last year's wages and the timing difference with regard to income date (1989) and residential location (1990) means that we may not have the real location of residence at the time the wage was earned. However, the over- 
whelming majority of our sample workers, 75 percent, have been in their residences for longer than two years, and even those who have changed residences in the last year may have done so in the same PUMA. As for differences across groups, Anglos and African-Americans were a bit less likely to have moved recently, with 80 percent in the same residence since 1988 versus about 70 percent of Asian Americans and Latinos; of the small number of full-time workers who were below the poverty line ( 3 percent of the sample), 60 percent had been in place since 1988 vs. 75 percent for the non-poor. Across PUMAs, the highest percentage of residents in place since 1988 was 88 percent while the lowest was 62 percent; however, the number of observations from each PUMA subsample is small. In any case, as long as the underlying movement pattern is somewhat random (any individual worker was equally likely to have relocated upward or downward the neighborhood income scale), then this potential measurement problem should cause no problem for our regression. Finally, if we exercise supreme caution and drop out of the regression samples all individuals not in the same residence since 1988, the general pattern of signs and significance and the various coefficient values are very similar.

22. The coefficients for the rate of return for each hour on the road suggests that individuals value their commuting time much less than its wage-measured opportunity cost, a result which is consistent with many transportation studies.

23. The actual variables are constructed by multiplying TRAVHRS by two dummy variables, with the first set equal to one for neighborhoods where the household poverty rate exceeds (or is equal to) 20 percent and zero otherwise, and the second set equal to one for all the other PUMAs and zero for all the "highpoverty" PUMAs.

24. If AVGTRHR is introduced, it has an unexpectedly positive sign although it is not significant by the usual standards. This unusual result may be due to the particular places of work we are constrained to in this very limited regression sample.

25. Note that it is the household head (or householder) that determines the length of residence for the household as a whole. This explains why IMM80s remains a relevant variable in Table 7 even when we cut back the sample to those households in place since 1978-these individuals joined previous households of long-term residents, presumably because of family ties, adding an additional element of exogeneity to the location decision as well an additional element of job networking via family members.

26. While not reported here, the spatial mismatch variable, AVGTRHR, is appropriately signed but generally insignificant for our long-time residents; the "best" run for AVGTRHR is column (d) where it obtains a significance level of .05 , but in all other runs it fails to obtain even a .10 level and is usually much less 
significant, especially when we are not directly testing for the effects of commuting. This may suggest that spatial mismatch matters less once residential roots are firm (job-housing patterns are already settled), but that social networks continue to matter.

27. When this housing model was estimated with OLS just to check explanatory power, all variables were signed as expected and significant and explanatory power was quite satisfactory.

28. In one set of runs, we used an interactive variable where, for example, AFAMPCT was equal to the percentage of African-American residents in the PUMA only for an African-American individual and zero otherwise; therefore, each observation had a self-group measure. The signs in such a housing location regression were as expected-increasing the percentage of a certain ethnic group in a PUMA attracts more members of that group-and the results for the wage regression which used these variables as instruments were virtually the same, with only the coefficient on AFAM being reduced in a substantial fashion.

29. Some workers live in group quarters while others pay zero rent, the log of which cannot be taken.

\section{REFERENCES}

Acs, Gregory, and Douglas Wissoker. "The Impact of Local Labor Markets on the Employmet Patterns of Young Inner-City Males." Washington, D.C.: The Urban Institute, 15 February 1991.

Cisneros, Henry G. Regionalism: The New Geography of Opportunity. Washington, DC: U.S. Department of Housing and Urban Development, 1995.

DeFreitas, Gregory. Inequality at Work: Hispanics in the U.S. Labor Force. New York: Oxford University Press, 1991.

Engberg, John B., and Taeil Kim. "Person or Place?: Sources of IntraMetropolitan Earnings Variation." Work in Progress. The Heinz School of Public Policy and Management, Carnegie Mellon University, December 1993.

Galster, George C., and Sean P. Killen. "The Geography of Metropolitan Opportunity: A Reconnaissance and Conceptual Framework." Washington, D.C.: The Urban Institute, 1994.

Ihlanfeldt, Keith R. "Spatial Mismatch and the Commutes, Employment, and Wages of Young Puerto Ricans Living in New York." Atlanta, Georgia: Policy Research Center, Georgia State University, 1992. 
Ihlanfeldt, Keith R., and David L. Sjoquist. "Job Accessibility and Racial Differences in Youth Employment Rates." The American Economic Review 80 (March 1990b): 267-276.

Ihlanfeldt, Keith R., and David L. Sjoquist. "The Effect of Residential Location on the Probability of Black and White Teenagers Having a Job." The Review of Regional Studies 20 (Winter 1990a): 10-20.

Kirschenmann, Joleen, and Kathyrn M. Neckerman. "'We'd Love to Hire Them, But ... .: The Meaning of Race for Employers." In Christopher Jencks and Paul E. Peterson (eds.) The Urban Underclass. Washington D.C.: The Brookings Institution, 1991: 203-232.

Logan, John R., and Richard D. Alba. "Locational Returns to Human Capital: Minority Access to Suburban Community Resources." Demography 30 (May 1993). 243-268.

McMillen, Daniel P., and Larry D. Singell, Jr. "Work Location, Residence Location, and the Intraurban Wage Gradient." Journal of Urban Economics 32 (September 1992): 195-213.

O'Regan, Katherine M. "The Effect of Social Networks and Concentrated Poverty on Black and Hispanic Youth Unemployment." The Annals of Regional Science 27 (December 1993): 327-342.

O’Regan, Katherine M., and John M. Quigley. "Labor Market Access and Labor Market Outcomes for Urban Youth." Regional Science and the Urban Economics 21 (1991): 277-293.

Pastor, Manuel Jr. Latinos and the Los Angeles Uprising: The Economic Context. Claremont, CA: The Toms Rivera Center, 1993.

Popkin, Susan J., James E. Rosenbaum, and Patricia M. Meaden. "Labor Market Experiences of Low-income Black Women in Middle-class Suburbs: Evidence from a Survey of Gautreaux Program Participants." Journal of Policy Analysis and Management 12, 3 (1993).

Price, Richard, and Edwin Mills. "Race and Residence in Earnings Determination." Journal of Urban Economics 17 (January, 1985): 1-18.

Sexton, Edwin A. "Residential Location, Workplace Location, and Black Earnings." The Review of Regional Studies 21 (Spring 1991): 11-20.

Wilson, William Julius. The Truly Disadvantaged: The Inner City, the Underclass, and Public Policy. Chicago: The University of Chicago Press, 1987. 